\title{
The effect of surface modification on the retention strength of polyetheretherketone crowns adhesively bonded to dentin abutments
}

\author{
Uhrenbacher, Julia ; Schmidlin, Patrick R ; Keul, Christine ; Eichberger, Marlis ; Roos, Malgorzata ; \\ Gernet, Wolfgang ; Stawarczyk, Bogna
}

\begin{abstract}
STATEMENT OF PROBLEM: The mechanical properties of polyetheretherketone (PEEK) make it an ideal material for fixed dental prostheses; however, insufficient information is available about the cementation of these restorations. PURPOSE: The purpose of this study was to evaluate the retention strength of differently pretreated and conditioned PEEK crowns luted to dental abutments. MATERIAL AND METHODS: Human teeth were prepared in a standardized manner, and PEEK crowns were milled ( $N=160, n=10$ per group) and conditioned as follows: airborne-particle abrasion, sulfuric etching, piranha etching, and no conditioning. These groups were divided into adhesive systems: visio.link, Signum PEEK Bond, Ambarino P60, and no adhesive and luted to dentin abutments. After water storage (60 days) and thermocycling $\left(5000\right.$ cycles, $\left.5^{\circ} \mathrm{C} / 55^{\circ} \mathrm{C}\right)$, the retention strength of the crowns was determined with a pull-off test, and failure types were classified. The data were analyzed with the Kruskal-Wallis, 1-way ANOVA, and (2) test (=.05). RESULTS: Crowns that were unconditioned and piranha etched and/or adhesively untreated or pretreated with Ambarino P60 had the lowest retention strength. The highest values were found for the airborne-particle abrasion and sulfuric etched groups and/or crowns adhesively pretreated with Signum PEEK Bond and visio.link. Composite resin cement that remained on dentin was observed more frequently for unconditioned groups in combination with Ambarino P60 and no adhesive pretreatment. Mixed failure types were found more frequently in the airborne-particle abrasion group in combination with visio.link, Signum PEEK Bond, and no adhesive pretreatment, in the sulfuric acid etched group combined with Ambarino P60 and no adhesive pretreatment, and after the piranha acid pretreatment in combination with visio.link or Signum PEEK Bond. CONCLUSIONS: The adhesion of the tested PEEK crowns to dentin was satisfactory after treatment with airborne-particle abrasion or etching with sulfuric acid and/or when additional adhesive systems such as visio.link or Signum PEEK Bond were used.
\end{abstract}

DOI: https://doi.org/10.1016/j.prosdent.2014.05.010

Posted at the Zurich Open Repository and Archive, University of Zurich

ZORA URL: https://doi.org/10.5167/uzh-104722

Journal Article

Accepted Version

Originally published at:

Uhrenbacher, Julia; Schmidlin, Patrick R; Keul, Christine; Eichberger, Marlis; Roos, Malgorzata; Gernet, Wolfgang; Stawarczyk, Bogna (2014). The effect of surface modification on the retention strength of polyetheretherketone crowns adhesively bonded to dentin abutments. Journal of Prosthetic Dentistry, 112(6):1489-1497. 
DOI: https://doi.org/10.1016/j.prosdent.2014.05.010 


\section{The effect of surface modification on the retention strength of PEEK crowns adhesively bonded to dentin abutments}

Short title: Retention strength of PEEK crowns

Julia Uhrenbacher, cand med dent, ${ }^{\mathrm{a}}$ Patrick R. Schmidlin, Prof Dr med dent, ${ }^{\mathrm{b}}$ Christine Keul, med dent, ${ }^{\mathrm{c}}$ Marlis Eichberger, ${ }^{\mathrm{d}}$ Malgorzata Roos, PhD, ${ }^{\mathrm{e}}$ Wolfgang Gernet, Prof Dr med dent Dr h.c, ${ }^{f}$ Bogna Stawarczyk, Dipl Ing MSc ${ }^{g}$

${ }^{\mathrm{a}}$ Dental Medicine Student, Department of Prosthodontics, Dental School, LudwigMaximilians-University of Munich. Performed experiments, wrote manuscript.

${ }^{b}$ Professor and Head of Periodontology, Clinic of Preventive Dentistry, Periodontology and Cariology, Center of Dental Medicine, University of Zurich, Switzerland. Contributed substantially to idea, discussion, proofread of manuscript.

${ }^{c}$ Assistant Professor, Department of Prosthodontics, Munich Dental School, LudwigMaximilians University Munich, Germany. Performed the fracture type analyses and figures, supported the $1^{\text {st }}$ author by surface measurements of dentin abutments, proofread of manuscript.

${ }^{\mathrm{d} D e n t a l}$ Technician, Department of Prosthodontics, Munich Dental School, LudwigMaximilians University Munich, Germany. Constructed and milled all PEEK crowns. ${ }^{\text {e }}$ Senior Statistician, Division of Biostatistics, Institute of Social and Preventive Medicine, University of Zurich, Switzerland. Conducted the power analysis, performed statistical analyses and proofread the manuscript.

${ }^{\mathrm{f}}$ Senior Materials Scientist, Department of Prosthodontics, Dental School, LudwigMaximilians-University of Munich. Idea, experimental design, hypothesis, co-wrote manuscript. Performed statistical analyses.

Keywords: retention strength, PEEK, adhesive system, surface treatment, acid etching, piranha solution

Correspondence: Dipl. Ing. Bogna Stawarczyk, MSc, Department of Prosthodontics, Dental School, Ludwig-Maximilians University Munich, Goethestrasse 70, 80336 Munich, Germany, Tel. +49-89-51609573, e-mail: bogna.stawarczyk@med.uni-muenchen.de 


\section{The effect of surface modification on the retention strength of PEEK crowns adhesively bonded to dentin abutments}

Statement of problem. The mechanical properties of polyetheretherketone (PEEK) make it an ideal material for fixed dental prostheses (FDPs); however, insufficient information is available about the cementation of these restorations.

Purpose. The purpose of this study was to evaluate the retention strength of differently pretreated and conditioned PEEK crowns luted to dental abutments.

Material and methods. Human teeth were prepared in a standardized manner and PEEK crowns were milled ( $\mathrm{N}=160, \mathrm{n}=10$ per group) and conditioned as follows: airborne-particle abrasion, sulfuric etching, piranha etching, and no conditioning. These were divided into adhesive systems: visio.link, Signum PEEK Bond, Ambarino P60, and no adhesive and luted to dentin abutments. After water storage (60 days) and thermocycling (5000 cycles, $\left.5^{\circ} \mathrm{C} / 55^{\circ} \mathrm{C}\right)$, the retention strength of the crowns was determined with a pull-off test, and failure types were classified. The data were analyzed with the Kruskal-Wallis, 1-way ANOVA, and $\mathrm{Chi}^{2}$ test $(\alpha=.05)$.

Results. Crowns which were unconditioned and piranha etched and/or adhesively untreated or pretreated with Ambarino P60 showed the lowest retention strength. The highest values were found for the airborne-particle abrasion and sulfuric etched groups and/or crowns adhesively pretreated with Signum PEEK Bond and visio.link. Composite resin cement remaining on dentin was observed more frequently for unconditioned groups in combination with Ambarino P60 and no adhesive pretreatment. Mixed failure types were found more frequently in the airborne-particle abrasion group in combination with visio.link, Signum PEEK Bond, and no adhesive pretreatment, in the sulfuric acid etched group combined with Ambarino P60 and no adhesive pretreatment, and after the piranha acid pretreatment in combination with visio.link or Signum PEEK Bond. 
Conclusions: The adhesion of the tested PEEK crowns to dentin was satisfactory after treatment with airborne-particle abrasion or etching with sulfuric acid and/or when additional adhesive systems such as visio.link or Signum PEEK Bond were used.

\section{CLINICAL IMPLICATIONS}

PEEK crowns should be airborne-particle abraded ( $50 \mu \mathrm{m}$ alumina particles) before cementation or etched with sulfuric acid (60 seconds). For conditioning of the PEEK surface, MMA-based adhesive systems can be used.

\section{INTRODUCTION}

Polyetheretherketone (PEEK) is a material that has attracted attention in medicine and is now gaining ground in the dental field. Studieshave focused on promoting the nonreactive PEEK surface to react with resins to enable the bonding of a PEEK restoration to the tooth in a manner that satisfies the requirements of durability, longevity, and stability in the oral cavity. ${ }^{1-8}$ Two aspects should be considered in the pretreatment of the PEEK surface to gain a better bond to the adhesive cement: the modification of the PEEK surface (pretreatment) and the application of an adhesive system (conditioning) to allow for chemical interactions with the cement material. ${ }^{9-11}$ Two studies have investigated the effect of surface pretreatment with sulfuric acid etching for 60 seconds. ${ }^{1,2}$ One study showed that etched PEEK surfaces and selfadhesive resin composite (RelyX Unicem) or a direct composite resin (Tetric) (18.2 \pm 5.4 to $19.0 \pm 3.4 \mathrm{MPa})$ showed higher bond strength compared to the titanium control group (8.7 $\pm 2.8 \mathrm{MPa}){ }^{1}$ A second study confirmed these findings when etching was done with sulfuric acid in combination with veneering resins (Gradia: $14.3 \pm 1.8 \mathrm{MPa}$ /Sinfony: $18.56 \pm 2.74$ $\mathrm{MPa}) .{ }^{2}$ While the sulfuric acid etched group showed the highest bond strength values, the silica-coated group demonstrated the highest wettability and roughness. The findings 
regarding sulfuric acid etching have been consistent, ${ }^{1-3}$ while investigations with piranha acid have led to contradictory conclusions. ${ }^{5,7}$ Pretreating PEEK surfaces with piranha solution in combination with airborne-particle abrasion with silica and alumina particles produced the highest tensile bond strength values to self-adhesive resin cement (RelyX Unicem; 3M ESPE) when the surface was airborne-particle abraded with $50 \mu \mathrm{m}$ alumina followed by etching with piranha solution (Clearfil Ceramic Primer; Kuraray Dental: 14.9 MPa/Heliobond; Ivoclar Vivadent: 21.4 MPa). ${ }^{5}$ In contrast, etching without airborne-particle abrasion led to significantly lower bond strength (Clearfil Ceramic Primer: 8.6 MPa/Heliobond: 11.8 MPa). Untreated PEEK surfaces showed no bonding to self-adhesive resin cement. In contrast, a follow-up study measured the bonding properties to veneering composite resin and observed no positive effect of piranha-acid treatment of the PEEK surface. ${ }^{7}$ The highest bond strength was found in the airborne-particle abrasion group (1.3 to $20.7 \mathrm{MPa})$ and after airborne-particle abrasion in combination with additional piranha etching (1.4 to 22.6 MPa). Groups etched with piranha acid only and untreated groups showed no adhesion to PEEK in combination with veneering resin cements. However, after the use of additional adhesive systems, an increase in bond values was observed. In general, adhesive systems containing MMA monomers showed durable tensile bond properties ( 7.6 to $69 \mathrm{MPa}$ ), even after aging. ${ }^{4,8}$ This was corroborated by another study, which found that airborne-particle abrasion in combination with MMA-monomer led to the highest shear bond strength (8.3 to $15.7 \mathrm{MPa}){ }^{6}$

Thermocycling is an appropriate method for the in vitro aging of specimens to test bonding properties, as the stress for all specimens is standardized and reproducible. ${ }^{12-17}$ Many studies have tested the bond strength immediately after specimen fabrication or after 24 hour water storage, ${ }^{4,5,8}$ which only leads to a limited amount of information. Studies so far have only investigated geometric specimens. Therefore, this study simulated a more realistic clinical environment, aiming to restore extracted human molar abutments with milled PEEK crowns and to assess the retention strength of those crowns with a pull-off test involving axial 
dislodgement forces after aging. ${ }^{18,19}$ The study also tested the effect of mechanical/chemical pretreatment and different adhesive systems on the retention strength. The null hypotheses stated that the pretreatment factor of the PEEK surface or the conditioning with adhesive systems had no effect on the retention strength values or failure types of crown retention.

\section{MATERIAL AND METHODS}

One-hundred-sixty extracted caries-free human molars were stored in a $0.5 \%$ chloramine-Tsolution (Chloramine-T; Sigma Aldrich) for the first 7 days after extraction and then in distilled water at a temperature of $5^{\circ} \mathrm{C}$ for a maximum of 6 months. They were cleaned and retention elements with an average diameter of approximately $2 \mathrm{~mm}$ were drilled into the roots. The roots were shortened to allow placement in an embedding mold (DR Tech; Daellenbach) in such a way that the enamel-dentin-junction was at the same height as the upper rim of the embedding mold. The screw-hole of the embedding mold was filled with a csilicone (Silicone modelling; Orbis Dental) to isolate it from the autopolymerizing acrylic resin (ScandiQuick; ScanDia). The teeth were positioned with dental boxing wax (Boxing wax sticks; Kerr, Sybron Dental Specialties, Lot. nr. 00609), and the embedding molds were filled with autopolymerizing acrylic resin to the upper rim. The screw-hole of the lower embedding mold was then removed, and the teeth were positioned in a custom-made device with a preparation angle of 10 degrees and prepared with a diamond rotary instrument (16 Torpedo; Komet Dental) in a parallelometer (F4-basic; DeguDent GmbH) with water-cooling. The abutments were reduced to a height of $3 \mathrm{~mm}$ with a cutting device (Secotom 50; Struers). Sharp edges were rounded (K-stone; Komet Dental).

The prepared teeth were scanned with a laboratory scanning device (Ceramill map 400; Amann Girrbach) after applying a scan spray (Arti-spray-white; Bausch). A crown with maximum retention was designed (ZENOtec Cam 3.2 Advanced; Wieland Dental + Technik) 
and then milled (I-mes 4020; Wieland Dental + Technik). In addition, the teeth were scanned with the Kavo Everest system (Kavo Everest Scan; KaVo) after scan spray application, and the acquired Standard Template Library (STL) data sets were imported into the software (Quality 12.1.2; Geomagic) used to calculate the prepared surface area. The crowns were then divided into 4 groups according to their pretreatments ( $n=40$ per group): airborne-particle abrasion, sulfuric acid etching, piranha acid etching, and no surface pretreatment (Fig. 1) mmediately after etching, the crowns were cleaned in an ultrasonic bath (Transistor/Ultrasonic T-14; L\&R) for 5 minutes. After drying, they were again subdivided according to their adhesive system ( $\mathrm{n}=10$ per subgroup): visio.link, Signum PEEK Bond, Ambarino P60, and no adhesive system. All adhesive systems were used according to the manufacturer's instructions (Table I). The crowns were then luted to the tooth abutments with self-adhesive resin cement (RelyX Unicem; 3M ESPE) with a seating force of $1 \mathrm{~N}$ during polymerization with a light-emitting diode (LED) unit (Elipar S10; 3M ESPE) at a light intensity of $1200 \mathrm{~mW} / \mathrm{cm}^{2}$ for 40 seconds. The specimens were then stored in water in an incubator (Hera cell 150; Heraeus Kulzer) for 60 days at $37^{\circ} \mathrm{C}$ and then underwent 5000 thermocycles (between $5 \pm 5^{\circ} \mathrm{C}$ and $55 \pm 5^{\circ} \mathrm{C}$; Thermocycler THE 1100; SD Mechatronik) with a 20 -second dwell time in each water bath.

For retention strength measurement, the teeth with their respective crowns were embedded in a second upper embedding mold. To ensure that both embedding molds were parallel to each other and that a standardized distance of $1.5 \mathrm{~mm}$ between them was respected, c-silicone was molded in such way that it covered the preparation margin, the resin used to embed the tooth, and the exposed metal surface of the embedding mold. This ensured that the pulling force was exerted on the upper crown only during the retention strength measurement. The screw-hole of the upper embedding mold was isolated with Vaseline (white Vaselin; Wasserfuhr). Autopolymerizing acrylic resin was poured into the embedding mold through this opening, thereby surrounding the crown only. For retention strength measurements, the 
specimens were fixed in a specially designed device for pull out tests in a universal testing machine (Zwick 1445; Zwick). Both embedding molds were pulled away from each other at a crosshead speed of $5 \mathrm{~mm} /$ minute until debonding of the crown was determined (Fig. 2). The maximum load immediately before debonding was recorded. The following formula was used to calculate retention strength values: fracture load/bond $=\mathrm{N} / \mathrm{mm}^{2}=\mathrm{MPa}$. The debonding surface was classified into groups as follows: mixed failure type, self-adhesive resin composite cement remnants on dentin and self-adhesive resin composite cement remnants in the crown.

The number of specimens was determined with a power analysis ( R, R Development Core Team; The R Foundation for Statistical Computing) from the data of a previous study, ${ }^{18}$ with a standard deviation of adhesively cemented resin crowns on dentin abutments of 0.22 MPa. A difference of $0.44 \mathrm{MPa}$ between 2 different testing groups was assumed to be relevant for the application of a 2-sample Student $t$ test based on the Bonferroni corrected significance level of .0083 according to 6 pair-wise comparisons among 4 pretreatment groups. The sample size of $\mathrm{n}=10$ for each tested group provided a power equal to $91.7 \%$.

The descriptive statistics for all tested groups were calculated. The KolmogorovSmirnov and Shapiro-Wilk tests were used to test the normality of the data distribution. The effect of pretreatment and/or conditioning with adhesive systems on the retention strength was investigated with the Kruskal-Wallis and 1-way ANOVA analysis followed by the Scheffé post hoc test. In addition, 1-way ANOVA followed by the Bonferroni post hoc test with respect to 1 factor with all 16 subgroup levels was computed. The linear regression was used to evaluate the gain with the corresponding $95 \%$ confidence interval (CI) in retention strength among calculated statistically different value ranges.

Relative frequencies of failure types together with the corresponding $95 \%$ CI estimated according to the Ciba Geigy tables were provided. The $\mathrm{Chi}^{2}$ test was used to analyze the 
distribution of failure types in different treatment groups. The statistical analyses were performed with the Statistical Package for the Social Science Version 20 (SPSS Inc) $(\alpha=.05)$.

\section{RESULTS}

Means, standard deviations (SD), and 95\% CIs are presented in Table II for each tested group according to the pretreatment method and adhesive system used. The tensile strength values are depicted by the boxplot diagram (Fig. 3). Kolmogorov-Smirnov and Shapiro-Wilk tests indicated no violation of the assumption of normality for $15(94 \%)$ of 16 groups. Only 6\% were not normally distributed, which is close to but larger than the error of the first kind for a statistical test. Therefore, both nonparametric and parametric analyses were conducted. The obtained p-values agreed well.

Within airborne-particle abraded and sulfuric acid etched groups, no effect of adhesive systems was observed $(P>.05)$. Groups etched using piranha acid and conditioned with visio.link and Signum PEEK Bond showed significantly higher retention strength than unconditioned groups and groups conditioned using Ambarino P60 $(P<.001)$. Among nonpretreated groups, groups conditioned using Ambarino P60 and groups not conditioned at all presented significantly lower values than groups conditioned with Signum PEEK Bond $(P<.001)$. However, Signum PEEK Bond and visio.link were not significantly different $(P>.05)$

Groups conditioned with visio.link showed significantly lower retention strength for nonpretreated PEEK surfaces than for treated ones $(P<.001)$. PEEK crowns, which were pretreated by airborne-particle abrasion, sulfuric acid etching, or piranha acid etching were in the same range of values $(P>.05)$. After conditioning with Signum PEEK Bond, the nonpretreated group showed significantly lower values than the airborne-particle abrasion group $(P<.001)$. However, the acid etched groups were not significantly different from the nonpretreated or airborne-particle abraded group $(P>.05)$. Nonconditioned groups and groups 
conditioned with Ambarino P60 showed a significantly lower retention strength without treatment and after pretreatment with piranha acid than groups etched with sulfuric acid or pretreated with air-abrasion $(P<.001)$.

The global 1-way ANOVA computed between all 16 subgroups presented 3 value ranges. All airborne-particle abraded and all sulfuric acid etched groups and piranha acid etching in combination with visio.link or Signum PEEK Bond (value range: 1) showed significantly higher retention strength than the non-pretreated groups conditioned with Signum PEEK Bond (value range: 2) $(P<.001)$. This group, however, presented significantly higher bond values than the piranha acid etched groups and non-pretreated groups when these were conditioned with Ambarino P60 or when not conditioned at all (value range: 3) $(P=.030)$. The gain in tensile strength of value range 1 to value range 2 was $0.57(0.04 ; 1.09)$ $\mathrm{N}$ and to value range 3 was $1.76(1.46 ; 2.01) \mathrm{N}$.

The tested groups showed different failure types (Table III) depending on the pretreatment method $(P<.001)$. A CI of $95 \%$ not containing more than $50 \%$ of one failure type as follows: Composite resin cement remaining on dentin was observed more frequently for untreated groups in combination with Ambarino P60 (90[54;100]\%) and without conditioning $(100[68 ; 100] \%)$. Mixed failure types were found most frequently in the airborne-particle abrasion group in combination with visio.link $(100[68 ; 100] \%)$, Signum PEEK Bond $(100(68 ; 100) \%)$ and no conditioning $(100(68 ; 100) \%)$. Mixed failure types were also found in the group pretreated with sulfuric acid and conditioned with Ambarino P60 (100[68;100]\%), in the group pretreated with sulfuric acid and not conditioned at all $(100[68 ; 100] \%)$, and in the group pretreated with piranha acid and then conditioned with visio.link $(100[68 ; 100] \%)$ or Signum PEEK Bond (100[68;100]\%) (Fig. 4).

\section{DISCUSSION}


This in vitro study examined the effect of different treatment methods, including mechanical and chemical surface pretreatments and/or the use of adhesive systems on computer-aided design and computer-aided manufacturing (CAD/CAM) milled PEEK crowns to increase the retention strength on a dentin abutment. All groups showed considerably lower retention strength when PEEK crowns were untreated. While airborne-particle abrasion and sulfuric acid etching increased the retention strength significantly, etching with piranha acid showed no effect.

In accordance with previous studies, this investigation confirmed that bond strength after airborne-particle abrasion increased compared to non-pretreated PEEK surfaces. ${ }^{1,5}$ Airborne-particle abrasion only increases the surface area of PEEK, while sulfuric acid or piranha acid altered the chemical characteristics of the surface, leading to an increased number of functional groups on the PEEK surface. ${ }^{5}$ The surface polarity increases when the oxygen in sulfuric acid and in the piranha acid reacts with and breaks the PEEK benzene ring so that more functional groups show bonding potential. ${ }^{5}$ This study observed a positive effect after sulfuric acid but not piranha acid application, with regard to the retention strength of PEEK crowns luted to a dentin abutment. Two other studies used the tensile bond strength test and found low bond strength results for piranha acid etched PEEK surfaces. ${ }^{5,7}$ However, in combination with airborne-particle abrasion, a significant increase in results was observed. Unlike piranha acid pretreatment, sulfuric acid on its own demonstrated a positive effect on bonding properties according to various studies. ${ }^{1,3,6}$ A further study examined the effect of different etching times of sulfuric acid on a PEEK surface, with regard to bond strength tested by using different resin composite cements. ${ }^{3}$ The authors stated that individual etching times should be considered for each resin composite material. In this study, PEEK crowns were etched with sulfuric acid for 60 seconds. Three other studies also used this etching time for sulfuric acid and also obtained 
durable bond strengths. ${ }^{1,2,7}$ The effect of piranha acid on a PEEK surface was found in only 1 study. ${ }^{5}$ In the present study, the surfaces were etched for 30 seconds. Airborne-particle abrasion and acid etching appear to clean and increase the surface area, resulting in higher bond strength due to mechanical retention..$^{1-3,9,10}$

With regard to the adhesive pretreatment, while Ambarino P60 had no impact on the retention strength, visio.link or Signum PEEK Bond led to an increase in values. The contents and solvents of the adhesive system play an important role in creating a bond to PEEK. Three previous studies examined the bond strength properties of PEEK materials and found that adhesive systems which contain MMA monomers, such as visio.link or Signum PEEK Bond, resulted in the higher bond strengths. ${ }^{46,7}$

In the current study, the highest adhesion was observed in groups conditioned with Signum PEEK Bond, a 2-step system. The first solution contains bifunctional molecules based on phosphoric acid esters and thiol compounds and is not light polymerized, while Bond II contains methyl methacrylate (MMA), polymethylmethacrylate (PMMA) as well as photoinitators and was light polymerized for 90 seconds. Also visio.link, which contains pentaerythritolthiacrylate (PETIA), MMA monomers, and dimethacrylate showed durable results. Therefore, it can be assumed that MMA caused the PEEK surface to swell and that the dimethacrylate monomers provided the connection to the composite resins with 2 carboxyl groups as binding sites. In contrast, the use of Ambarino P60, which contains acid groups such as phosphor/phosphon acid ester combined with dimethacrylate, resulted in no or minute retention strengths. This suggests that 1 functional group of the bifunctional monomer is occupied by an acid group which cannot further chemically react with the PEEK substrate or the composite resin. The reason for the lack of adhesion between PEEK and Ambarino P60 could be a lack of MMA monomers. The adhesive failure types between the cement and PEEK crowns as well as mixed failures showed that the adhesion of these cements to the 
dentin was higher than to the crowns. Furthermore, no adhesive failure types of PEEK crowns were observed. Therefore, both aspects of the null hypothesis of this study, which stated that pretreatment or conditioning with different adhesive systems of PEEK surfaces has no effect on the retention strength results and failure types, were rejected.

These results corroborate previous studies which applied shear and tensile bond strength test methods. However, the results found in the current pull-off tests were lower than those of these previous studies. Therefore, the test method affects the bonding properties as well.

With regard to the methodology, extracted human molars were prepared and used as abutments to simulate a clinical situation. However, studies using geometric specimens can produce more standardized specimens, with less variability. A significant shortcoming of this study is the fact, that no intrapulpal pressure was simulated, which might interfere with the bonding. Therefore, results are not generally applicable, at least not for vital teeth.

In 2 previous studies, the retention strength of zirconia crowns $(7.3 \text { to } 14.1 \mathrm{MPa})^{20}$ and polymeric $\mathrm{CAD} / \mathrm{CAM}$ crowns cemented with self-adhesive resin cements on dentin were tested $(0 \text { to } 2.8 \mathrm{MPa})^{18}$. Although the identical experimental design was used, the results of this study indicated similar values to those of adhesively cemented polymeric CAD/CAM crowns. However, the bonding properties to zirconia crowns were higher.

For pull-off-tests, the bonding area $\left(\mathrm{mm}^{2}\right)$ and the force $(\mathrm{N})$ required for debonding are the 2 main factors that determine the retention strength (MPa). Various studies have used different methods to determine the bonding area of the abutment. ${ }^{18-23}$ In this study, the tooth surface was scanned, and the STL-datasets were analyzed. Scanning the surface with a computer system is a more precise approach to surface area calculation than methods used in other studies. It also means that the bonding areas were calculated compared to other methods and estimations. 
The aging in the present study consisted of water storage for 60 days at $37^{\circ} \mathrm{C}$ and thermocycling for 5000 thermal cycles $\left(5^{\circ} \mathrm{C} / 55^{\circ} \mathrm{C}\right.$; dwell time, 20 seconds). The effect of thermocycling on the retention strength of the differently pretreated and conditioned PEEK crowns plays an important role in long-term predictability. Thermal cycling is an adequate method for the laboratory simulation of intraoral thermal variations caused by eating, drinking ${ }^{12}$ and breathing. ${ }^{13}$ By this procedure, all specimens underwent a standardized and reproducible stress. No direct translation of in vitro thermocycling to the clinical situation has been made. A meta-analysis investigated the effect of thermocycling in previous studies regarding applied temperature, dwell time, and the number of cycles applied. ${ }^{14}$ In all reviewed studies, $5^{\circ} \mathrm{C}$ and $55^{\circ} \mathrm{C}$ were the median values of the applied temperature (range: $0^{\circ} \mathrm{C}$ to $36^{\circ} \mathrm{C}$ and $40^{\circ} \mathrm{C}$ to $\left.100^{\circ} \mathrm{C}\right)$.

The power analysis was performed with the data of a previous study ${ }^{18}$ which tested the retention strength of polymeric crowns under the same conditions. However, the cemented crowns were PMMA-based and not PEEK-based. After completing our study, we found that our assumptions during the planning phase were too optimistic. In fact, we observed both larger standard deviations and larger differences between the groups than planned. Therefore, we performed a post hoc power analysis with the data obtained to determine whether the sample size of $n=10$ in each group was sufficient for the hypotheses. The observed pooled standard deviations, the observed maximal differences, and the computed power estimates were as follows: For each factor separately: Hypothesis 1: Test differences between 4 adhesive systems: Airborne, $\mathrm{SD}($ pooled $)=0.80 \mathrm{MPa}, \mathrm{Diff}=1.03 \mathrm{MPa}$, power=48\%; Sulfuric, $\mathrm{SD}($ pooled $)=0.87 \mathrm{MPa}$, Diff=0.63 MPa, power=12\%; Piranha, SD(pooled)=1.18 MPa, Diff=2.10 MPa, power $=82 \%$; Without, $\mathrm{SD}($ pooled $)=0.36 \mathrm{MPa}, \mathrm{Diff}=\mathbf{0 . 6 6} \mathrm{MPa}$, power $=85 \%$. 
For each factor separately: Hypothesis 2: Test differences between 4 pretreatments: visio.link, SD(pooled)=0.79 MPa, Diff=1.85 MPa, power=98\%; Signum PEEK Bond, $\mathrm{SD}($ pooled $)=0.86 \mathrm{MPa}$, Diff=1.94 MPa, power=97\%; Ambarino P60, SD $($ pooled $)=0.69$ MPa, Diff=1.84 MPa, power=99\%; Without, SD(pooled) $=0.57 \mathrm{MPa}$, Diff=2.08 MPa, power $=99 \%$.

For each of the tests dealing with hypothesis 2 , excellent power was provided given pooled SD and data differences. For the piranha acid and no pretreatment groups, the tests for Hypothesis 1 showed good power, whereas the groups for visio.link and Signum PEEK Bond were underpowered. Therefore, for visio.link and Signum PEEK Bond the lack of significant results may have been due to an insufficient sample size given the spread in the data and the observed differences. Consequently, non significant results in these groups should be interpreted with caution.

In summary, the PEEK crowns showed significantly lower tensile strength than zirconia crowns. In order to achieve adequate, long-term adhesion clinically, the bonding to PEEK must be improved. Therefore, further studies should test other pretreatment methods for PEEK, such as other etching solutions, silanisation techniques, silica coating, and the application of other adhesive systems. Finally, clinical studies must be performed to validate these results.

\section{CONCLUSION}

Within the limitations of this study, airborne-particle abrasion and sulfuric acid etching of PEEK crowns should be recommended before luting PEEK crowns. The application of adhesive systems such as Signum PEEK Bond or visio.link increases the retention strength of PEEK crowns. 


\section{ACKNOWLEDGEMENT}

The authors would like to thank nt-trading, bredent, Heraeus Kulzer, Creamed and EM ESPE for supporting this study with materials.

\section{REFERENCES}

1. Schmidlin PR, Stawarczyk B, Wieland M, Attin T, Hämmerle CH, Fischer J. Effect of different surface pretreatment and luting materials on shear bond strength to PEEK. Dent Mater 2010;26:553-9.

2. Stawarczyk B, Beuer F, Wimmer T, Jahn D, Sener B, Roos M, Schmidlin PR. Polyetheretherketone- a suitable material for fixed dental prostheses? J Biomed Mater Res B Appl Biomater 2013;101:1209-16.

3. Sproesser O, Schmidlin PR, Uhrenbacher J, Roos M, Gernet W, Stawarczyk B. Impact of sulfuric acid etching duration of PEEK on the shear bond strength to different resin composite. J Adhes Dent 2013; submitted.

4. Stawarczyk B, Keul C, Beuer F, Roos M, Schmidlin PR. Tensile bond strength of veneering resins to PEEK: Impact of different adhesives. Dent Mater J 2013;32:441-8.

5. Hallmann L, Mehl A, Sereno N, Hämmerle C. The improvement of adhesive properties of PEEK through different pretreatments. Applied Surface Science 2012;258:7213-8.

6. Stawarczyk B, Bähr N, Beuer F, Wimmer T, Eichberger M, Gernet W, Jahn D, Schmidlin PR. Influence of plasma on shear bond strength of self-adhesive resin cements to polyetheretherketone. Clin Oral Investig 2014;18:163-70.

7. Keul C, Liebermann A, Schmidlin PR, Roos M, Sener B, Stawarczyk B. Influence of PEEK surface modification on the retention of two veneering resin composites. $J$ Adhes Dent 2013; submitted.

8. Kern M, Lehmann F. Influence of surface conditioning on bonding to polyetheretherketon (PEEK). Dent Mater 2012;28:1280-3. 
9. Ersu B, Yuzugullu B, Ruya Yazici A, Canay S. Surface roughness and bond strengths of glass-infiltrated alumina-ceramics prepared using various surface treatments. J Dent 2009;37:848-56.

10. Marshall SJ, Bayne SC, Baier R, Tomsia AP, Marshall GW. A review of adhesion science. Dent Mater 2010;26:e11-6.

11. Oilo G. Bond strength testing - what does it mean. Int Dent J 1993;43:492-8.

12. Palmer DS, Barco MT, Billy EJ. Temperature extremes produced orally by hot and cold liquids. J Prosthet Dent 1992;67:325-7.

13. Boehm RF. Thermal environment of teeth during open mouth respiration. J Dent Res $1972 ; 51: 75-8$.

14. Gale MS, Dervell BW. Thermal cycling process for laboratory testing of dental restorations. J Dent 1999;27;89-99.

15. Piwowarczyk A, Lauer HC, Sorensen JA. In vitro shear bond strength of cementing agents to fixed prosthodontic restorative materials. J Prosthet Dent 2004;92:265-73.

16. Nakamura T, Wakabayashi K, Kinuta S, Nishida H, Miyamae M, Yatani H. Mechanical properties of new self-adhesive resin-based cement. J Prosthodont Res 2010;54:59-64.

17. Torstenson B, Brannstrom M. Contraction gap under composite resin restorations: effect of hygroscopic expansion and thermal stress. Oper Dent 1988;13:24-31.

18. Stawarczyk B, Basler T, Ender A, Roos M, Özcan M, Hämmerle C. Effect of surface conditioning with airborne-particle abrasion on the tensile strength of polymeric CAD/CAM crowns luted with self-adhesive and conventional resin cements. J Prosthet Dent 2012;107:94-101.

19. Ernst CP, Cohnen U, Stender E, Willershausen B. In vitro retentive strength of zirconium oxide ceramic crowns using different luting agents. J Prosthet Dent $2005 ; 93: 551-8$. 
20. Stawarczyk B, Hartmann L, Hartmann R, Roos M, Ender A, Özcan M, Sailer I, Hämmerle CHF. Impact of Gluma Desensitizer on the tensile strength of zirconia crowns: An in-vitro study. Clin Oral Investig 2012;16:201-13.

21. Ernst CP, Wenzl N, Stender E, Willershausen B. Retentive strengths of cast gold crowns using glass ionomer, compomer, or resin cement. J Prosthet Dent 1998;79:4726.

22. Yim NH, Rueggeberg FA, Caughman WF, Gardner FM, Pashley DH. Effect of dentin desensitizers and cementing agents on retention of full crowns using standardized crown preparations. J Prosthet Dent 2000;83:459-65.

23. Palacios RP, Johnson GH, Phillips KM, Raigrodski AJ. Retention of zirconium oxide ceramic crowns with three types of cement. J Prosthet Dent 2006;96:104-14.

24. Heintze SD. Review: Crown pull-off test (crown retention test) to evaluate the bonding effectiveness of luting agents. Dent Mater 2010;26:193-206. 
Figure 1. Classification of the specimens in test groups with respect to pretreatment and adhesive system used.

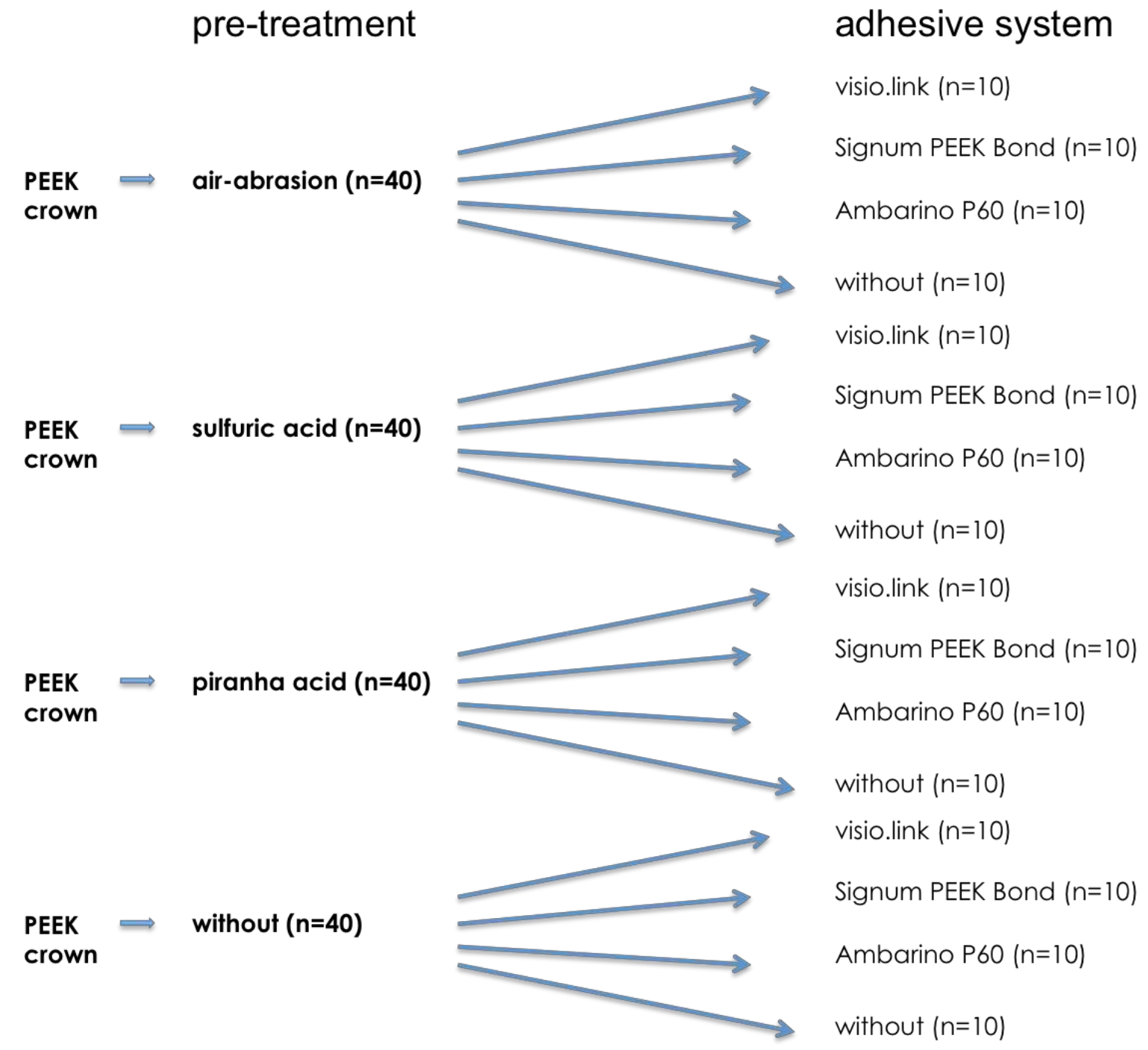


Figure 2. Measured retention strength of cemented PEEK crowns on teeth abutment for each pre-treatment and adhesive system, separately.

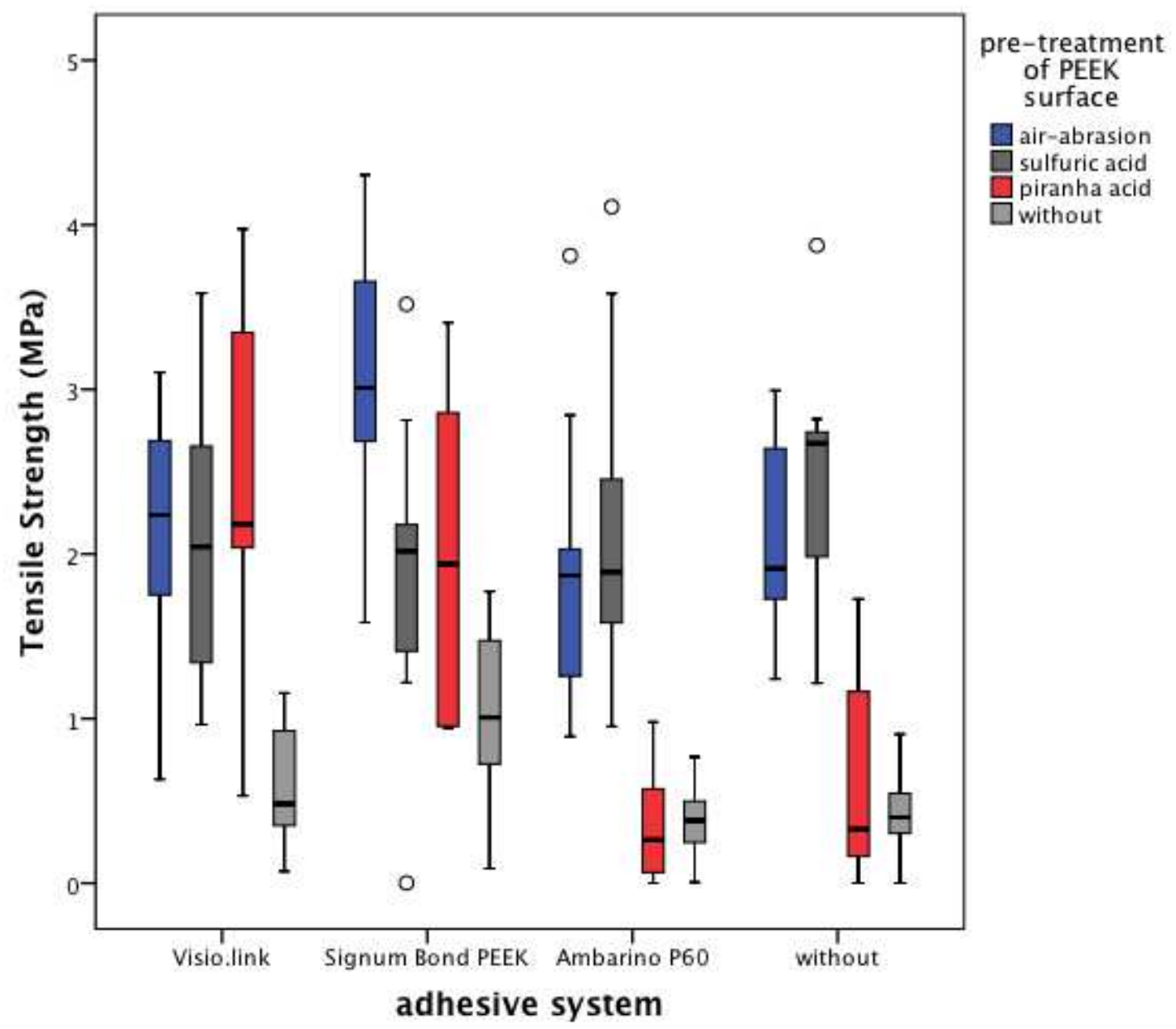


Figure 3. Failure types after retentions strength measurements: a. and b. resin composite cement remaining on dentin; c. and d. mixed failure types.

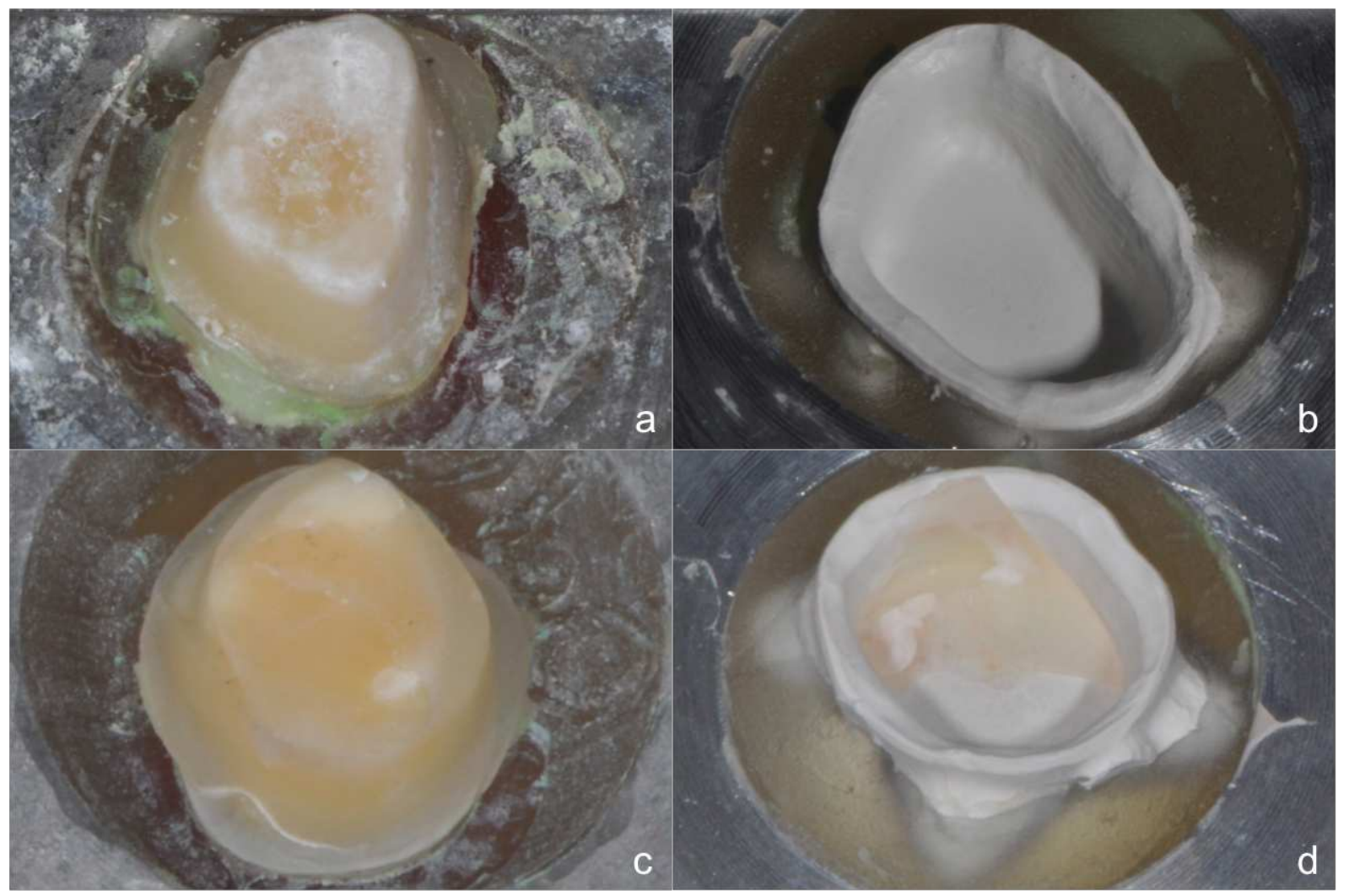


Table I: Materials, their manufacturers, compositions, Lot No, and form of application used in this study.

\begin{tabular}{|c|c|c|c|c|c|c|}
\hline & $\begin{array}{l}\text { Product } \\
\text { Name }\end{array}$ & Manufacturer & Composition & $\begin{array}{l}\text { Application steps as } \\
\text { recommended }\end{array}$ & Lot. No. & $\begin{array}{l}\text { Curing } \\
\text { light } \\
\text { applied }\end{array}$ \\
\hline \multicolumn{7}{|c|}{ Pretreatment/adhesive systems } \\
\hline $\begin{array}{l}\text { Airborne } \\
\text {-particle } \\
\text { abrasion }\end{array}$ & $\begin{array}{l}\text { alumina } \\
\text { powder }\end{array}$ & Orbis Dental & $\begin{array}{l}50 \mu \mathrm{m} \text { mean } \\
\text { particles }\end{array}$ & $\begin{array}{l}45^{\circ}, 10 \mathrm{~s} \\
\text { sandblaster (Basic } \\
\text { Quattro IS; Renfert, } \\
\text { Hilzingen, } \\
\text { Germany) }\end{array}$ & 20122617 & \\
\hline $\begin{array}{l}\text { Sulfuric- } \\
\text { acid }\end{array}$ & & & $98 \% \mathrm{H}_{2} \mathrm{SO}_{4}$ & $\begin{array}{l}\text { application for } 60 \mathrm{~s} \\
\text { Rinsing with } \\
\text { distilled water for } \\
60 \mathrm{~s}\end{array}$ & $\begin{array}{l}\text { CAS Nr.: } \\
7664-93-9\end{array}$ & \\
\hline $\begin{array}{l}\text { Piranha- } \\
\text { acid }\end{array}$ & & & $\begin{array}{l}3 \text { parts } 30 \% \\
\mathrm{H}_{2} \mathrm{O}_{2}, \text { to } 10 \\
\text { parts } 96 \% \\
\mathrm{H}_{2} \mathrm{SO}_{4}\end{array}$ & $\begin{array}{l}\text { application for } 30 \mathrm{~s} \\
\text { rinsing with } \\
\text { distilled water for } \\
30 \mathrm{~s}\end{array}$ & $\begin{array}{l}\text { CAS Nr.: } \\
\mathrm{H}_{2} \mathrm{O}_{2}: 7722- \\
84-1\end{array}$ & \\
\hline \multirow[t]{3}{*}{$\begin{array}{l}\text { Adhesive } \\
\text { system }\end{array}$} & visio.link & Bredent & $\begin{array}{l}\text { PETIA, MMA, } \\
\text { dimethacrylate, } \\
\text { photoinitiators }\end{array}$ & $\begin{array}{l}\text { Adhesive applied to } \\
\text { PEEK surface with } \\
\text { microbrush and } 90 \\
\text { s light polymerized }\end{array}$ & 112784 & $\begin{array}{l}\text { Brelux } \\
\text { Power } \\
\text { Unit, } \\
\text { bredent }\end{array}$ \\
\hline & $\begin{array}{l}\text { Signum } \\
\text { PEEK Bond }\end{array}$ & $\begin{array}{l}\text { Heraeus } \\
\text { Kulzer }\end{array}$ & $\begin{array}{l}\text { Bond I: } \\
\text { bifunctional } \\
\text { molecules based } \\
\text { on phosphoric } \\
\text { acid esters and } \\
\text { thiol compounds } \\
\text { Bond II: MMA, } \\
\text { PMMA, } \\
\text { photoinitators }\end{array}$ & $\begin{array}{l}\text { 1. Adhesive } 1 \text { is } \\
\text { applied to surface } \\
\text { and left for } 10 \mathrm{~s} \\
\text { 2. Adhesive } 2 \text { is } \\
\text { applied and light } \\
\text { polymerized for } 90 \\
\mathrm{~s}\end{array}$ & $\begin{array}{l}\text { Bond 1: } \\
010121 \\
\text { Bond 2: } \\
010110\end{array}$ & $\begin{array}{l}\text { HiLite } \\
\text { Power, } \\
\text { Heraeu } \\
\text { s } \\
\text { Kulzer }\end{array}$ \\
\hline & $\begin{array}{l}\text { Ambarino } \\
\text { P60 }\end{array}$ & Creamed & $\begin{array}{l}\text { dimethacrylate } \\
\text { based on } \\
\text { phosphor } \\
\text { acidesters and } \\
\text { phosphon } \\
\text { acidesters }\end{array}$ & $\begin{array}{l}\text { applied to PEEK } \\
\text { surface and left for } \\
120 \mathrm{~s}\end{array}$ & $\begin{array}{l}20110- \\
04057\end{array}$ & \\
\hline
\end{tabular}


Table II. Descriptive statistics for all measured retention strength results.

\begin{tabular}{|c|c|c|c|}
\hline $\begin{array}{l}\text { Pretreatment of } \\
\text { PEEK surface }\end{array}$ & Adhesive system used & $\begin{array}{l}\text { Mean retention } \\
\text { strength } \pm \mathrm{SD}[\mathrm{MPa}]\end{array}$ & $95 \% \mathrm{CI}[\mathrm{MPa}]$ \\
\hline \multirow{4}{*}{$\begin{array}{l}\text { Airborne-particle } \\
\text { abrasion }\end{array}$} & visio.link & $2.12 \pm 0.78^{\mathrm{a} / \mathrm{B}}$ & $(1.50 ; 2.72)$ \\
\hline & Signum PEEK Bond & $2.97 \pm 0.92^{\mathrm{a} / \mathrm{B}}$ & $(2.25 ; 3.68)$ \\
\hline & Ambarino P60 & $1.94 \pm 0.87^{\mathrm{a} / \mathrm{B}}$ & $(1.30 ; 2.56)$ \\
\hline & Without & $2.09 \pm 0.58^{\mathrm{a} / \mathrm{B}}$ & $(1.67 ; 2.51)$ \\
\hline \multirow[t]{4}{*}{ Sulfuric acid } & visio.link & $2.06 \pm 0.80^{\mathrm{a} / \mathrm{B}}$ & $(1.47 ; 2.63)$ \\
\hline & Signum PEEK Bond & $1.88 \pm 0.95^{\mathrm{a} / \mathrm{AB}}$ & $(1.18 ; 2.56)$ \\
\hline & Ambarino P60 & $2.18 \pm 0.99^{\mathrm{a} / \mathrm{B}}$ & $(1.46 ; 2.90)$ \\
\hline & Without & $2.51 \pm 0.70^{\mathrm{a} / \mathrm{B}}$ & $(1.99 ; 3.01)$ \\
\hline \multirow[t]{4}{*}{ Piranha acid } & visio.link & $2.44 \pm 1.07^{\mathrm{a} / \mathrm{B}}$ & $(1.66 ; 3.21)$ \\
\hline & Signum PEEK Bond & $2.01 \pm 0.98^{\mathrm{a} / \mathrm{AB}}$ & $(1.19 ; 2.81)$ \\
\hline & Ambarino P60 & $0.34 \pm 0.33^{\mathrm{b} / \mathrm{A}}$ & $(0.09 ; 0.58)$ \\
\hline & Without & $0.58 \pm 0.64^{\mathrm{b} / \mathrm{A}}$ & $(0.11 ; 1.04)^{*}$ \\
\hline \multirow[t]{4}{*}{ Without } & visio.link & $0.59 \pm 0.35^{\mathrm{ab} / \mathrm{A}}$ & $(0.33 ; 0.85)$ \\
\hline & Signum PEEK Bond & $1.03 \pm 0.53^{\mathrm{b} / \mathrm{A}}$ & $(0.64 ; 1.41)$ \\
\hline & Ambarino P60 & $0.37 \pm 0.22^{\mathrm{a} / \mathrm{A}}$ & $(0.21 ; 0.53)$ \\
\hline & Without & $0.43 \pm 0.24^{\mathrm{a} / \mathrm{A}}$ & $(0.25 ; 0.60)$ \\
\hline
\end{tabular}

*not normally distributed

${ }^{\mathrm{ab}}$ significant differences between adhesive systems within 1 pretreatment

${ }^{\mathrm{AB}}$ signicant differences between pretreatments within 1 adhesive system 
Table III. Absolute failure type frequencies of all tested groups after retention strength measurements.

\begin{tabular}{|c|c|c|c|}
\hline $\begin{array}{l}\text { Pretreatment of } \\
\text { PEEK surface }\end{array}$ & Adhesive system & Mixed failure types & $\begin{array}{l}\text { Self-adhesive composite } \\
\text { cement remains on dentin }\end{array}$ \\
\hline \multirow{4}{*}{$\begin{array}{l}\text { Airborne-particle } \\
\text { abrasion }\end{array}$} & visio.link & 10 & 0 \\
\hline & Signum PEEK Bond & 10 & 0 \\
\hline & Ambarino P60 & 8 & 2 \\
\hline & Without & 10 & 0 \\
\hline \multirow[t]{4}{*}{ Sulfuric acid } & visio.link & 8 & 2 \\
\hline & Signum PEEK Bond & 8 & 2 \\
\hline & Ambarino P60 & 10 & 0 \\
\hline & Without & 10 & 0 \\
\hline \multirow[t]{4}{*}{ Piranha acid } & visio.link & 10 & 0 \\
\hline & Signum PEEK Bond & 10 & 0 \\
\hline & Ambarino P60 & 2 & 8 \\
\hline & Without & 5 & 5 \\
\hline \multirow[t]{4}{*}{ Without } & visio.link & 2 & 8 \\
\hline & Signum PEEK Bond & 3 & 7 \\
\hline & Ambarino P60 & 1 & 9 \\
\hline & Without & 0 & 10 \\
\hline
\end{tabular}

